\title{
Methods for Determining the Safety Distance in the Urban Land Planning
}

\author{
Xingwei Sun* \\ Beijing, China \\ Sunxingwei0721@163.com
}

\begin{abstract}
With the rapid advance of Chinese cities constructions, the lack of urban land is going increasingly. While in urban planning, people should avoid the hidden active faults, because they directly triggered a variety of geological disasters such as rupture, earthquakes. In order to solve this contradiction, this article uses the Okada dislocation theory to calculate the surface rupture when hidden active fault moves, compared safety avoidance distance of adjacent point displacement and the total displacement, which shows the surface displacement of adjacent points difference method can both ensure safety and improve land utilization rate. At last, use Yanqing as an example to carry on the whole method.
\end{abstract}

Keywords-buried active fault; Okada; safety distance; Yanqing district

\section{INTRODUCTION}

Active fault means the fault has been active since 100 thousand years. A lot of examples indicate that active fault causes earthquakes. Especially when they are stronger than 7.0magnitude quake, they lead to huge cracks over surface. However aseismic measures are difficult to prevent facilities from direct damage. Earthquake spreads along seismogenic fault in narrow strip, so that it is difficult for the buildings near earthquakes to avoid destructions only with shockproof designs. According to some roles, there should be 200-500 meters at least between buildings and faults, so the first strategy is "to avoid" live faults when people do urban constructions. Now in China, insufficient of land resources and strict farmland protection policies limit rapid economic development and urbanization, so traditional standard cannot meet the intensify requirements. How to plan urban rationally and ensure the safety, increasing utilization becomes very important, so it is significance calculate precise position and distance away from active faults.

This paper is based on the Elastic Half Space Earthquake Fault Dislocation Theory (Okada Dislocation Theory). First, discuss the calculation of the three kinds of basic urban hidden active fault model when earthquake happens, and then compare land using rate of adjacent surface displacement difference and the total surface displacement. Finally, take Yanqing as an example, combining geological knowledge with seismic station data in city modes which can increase the land using rate and ensure the construction safety.

\section{HidDEN ACtive FAULT to SeISMiC Rupture Zone}

\section{A. Basic Theory of Dislocation Theory}

In 20th century, seismologist found earthquake occurs on fault, so the fault becomes the core of seismology theory. At the same time, the development of the Coseismic Deformation of the Quasi-static Dislocation Theory is the Theory of Dislocation. Steketee introduced Dislocation Theory to seismic deformation field in 1958, after several years development, Okada (1985) summarized previous researches, giving the Theory of Dislocation general expressions caused by fault surface and displacement of the earth's interior field:

$$
\iint_{\Sigma} \Delta \mu_{j}\left[\lambda \delta_{j k} \frac{\partial \mu_{i}^{n}}{\partial \xi_{n}}+\mu\left(\frac{\partial \mu_{i}^{j}}{\partial \xi_{k}}+\frac{\partial \mu_{i}^{k}}{\partial \xi_{j}}\right)\right] v_{k} d \Sigma
$$

$\delta_{j k}$ is the symbol of Kronecker, $\lambda$ and $\mu$ is Lame Constant, $v_{k}$ is fault plane normal vector components, $\mu_{i}^{j}$ is $\left(\xi_{1}, \xi_{2}, \xi_{3}\right)$ amplitude of $F$ of the focal points of $j$ components in point $\left(x_{1}, x_{2}, x_{3}\right)$, which is the component displacement of $\mathrm{i}$.

For the displacement of surface, an arbitrary point can use two components to describe $\left(h_{i}, Z_{i}\right) ; h_{i}$ is maximum displacement vector; $Z_{i}$ is the vertical component. Therefore, the point in the space of the total displacement $d_{i}$ can be calculated by the horizontal displacement vector and vertical displacement vector:

$$
d_{i}=\sqrt{\left|h_{i}\right|^{2}+z_{i}^{2}}
$$

For two adjacents in space, if their displacement vectors are the same, and there is no relative deformation; while they are not the same, they cause relative deformation. Radial displacement difference vector is $\Delta h_{i}=h_{i+1}-h_{i}$; vertical displacement difference is $\Delta \mathrm{z}_{i}=\mathrm{z}_{i+1}-\mathrm{z}_{i}$; the total displacement difference is $\Delta d_{i}$ :

$$
\Delta d_{i}=\sqrt{\left|\Delta h_{i}\right|^{2}+\Delta z_{i}^{2}}
$$




\section{B. Surface displacement difference of four hidden active fault types}

Earthquake surface rupture area is seismogenic active fault dislocation which damages the surface directly. According to moving directions, they can be divided into strike slip fault and dip-slip fault. Fault types and structural characteristics are important factors to influence the distribution of earthquakes.
TABLE I. shows the parameters of elastic half space expressions of Okada Dislocation Theory. Geometrical and seismic source parameters are given in table, choosing $2 \mathrm{~m}$ as dislocation, equal to a 7.0-magnitude quake, and the dislocation direction is affected by the characters of fault.

TABLE I. This CAPTION IS Placed OUTSIDE THE FRAME AND IS Followed by A PAGE BREAK

\begin{tabular}{c|cccccccc}
\hline Property & $\begin{array}{c}\text { Hidden } \\
\text { Depth }\end{array}$ & Trend & Angle & $\begin{array}{c}\text { Plane } \\
\text { Extension }\end{array}$ & $\begin{array}{c}\text { Depth } \\
\text { Extension }\end{array}$ & $\begin{array}{c}\text { Moving } \\
\text { Direction }\end{array}$ & Dislocation & Rank \\
\hline $\begin{array}{c}\text { Normal } \\
\text { Fault }\end{array}$ & $2 \mathrm{~m}$ & $30^{\circ}$ & $70^{\circ}$ & $5 \mathrm{~m}$ & $3 \mathrm{~m}$ & $-90^{\circ}$ & $2 \mathrm{~m}$ & 7 \\
$\begin{array}{c}\text { Reversed } \\
\text { Fault } \\
\text { eft Lateral }\end{array}$ & $2 \mathrm{~m}$ & $30^{\circ}$ & $30^{\circ}$ & $5 \mathrm{~m}$ & $3 \mathrm{~m}$ & $90^{\circ}$ & $2 \mathrm{~m}$ & 7 \\
$\begin{array}{c}\text { Anti- } \\
\text { clockwise } \\
\begin{array}{c}\text { Right } \\
\text { lateral } \\
\text { clockwise }\end{array}\end{array}$ & $2 \mathrm{~m}$ & $30^{\circ}$ & $90^{\circ}$ & $5 \mathrm{~m}$ & $3 \mathrm{~m}$ & $0^{\circ}$ & $2 \mathrm{~m}$ & 7 \\
\hline
\end{tabular}
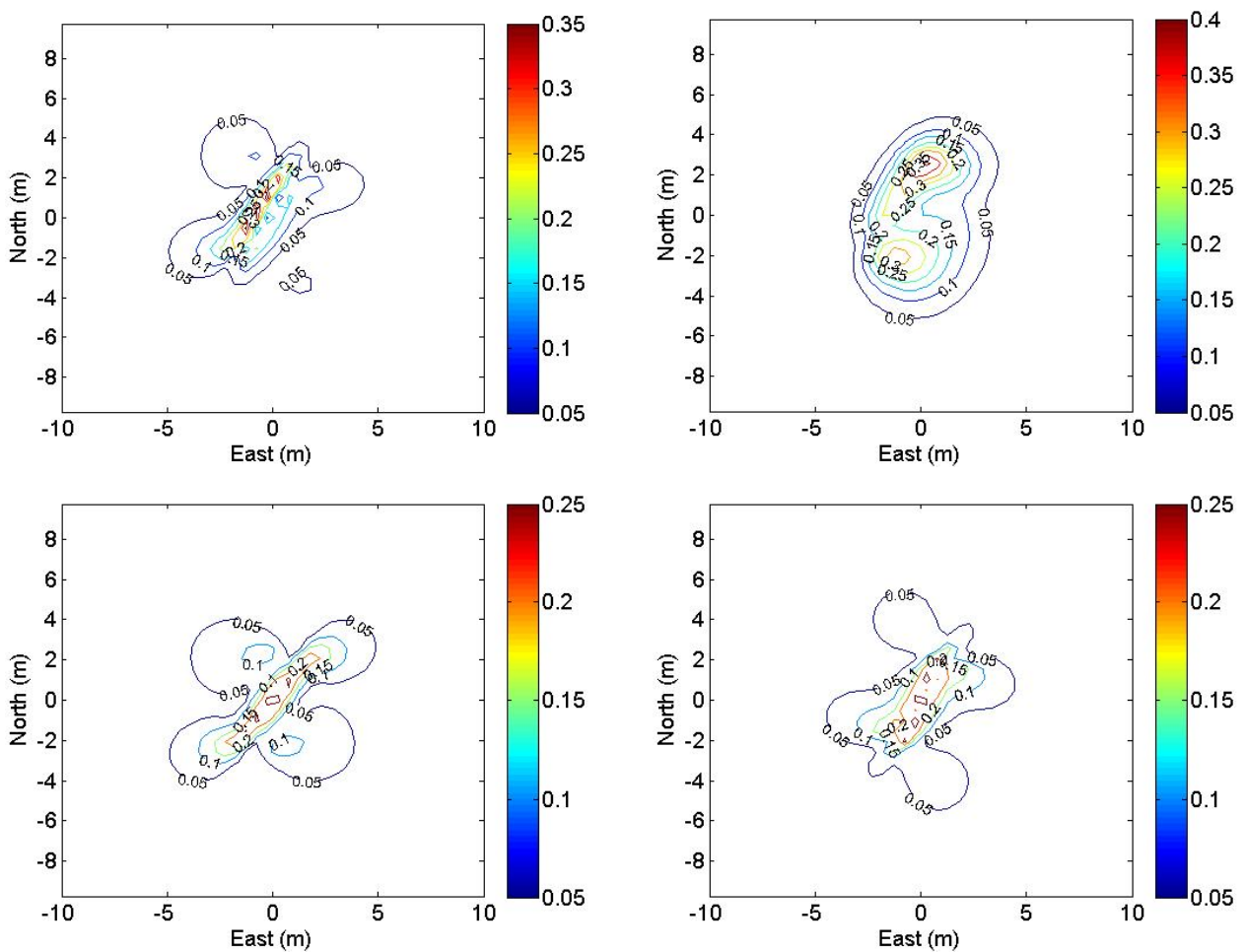

Fig. 1. The Surface Displacement Difference Contour Map of Hidden Active Fault Model (upper left is normal fault, right upper left is reverse fault, left down is Left Lateral Anti-clockwise, right down is Right lateral clockwise).

Surface ruptures due to the displacement of any difference between two adjacent to critical values which is $0.1 \mathrm{~m}$. According to Fig. 1., using $0.1 \mathrm{~m}$ as critical value of avoiding belt, the difference distribution set a total amount of displacement on the surface distribution of adjacent surface displacement. Comparing to the traditional method, this method can improve the land utilization rate. A large percentage of buildings damaged in earthquake due to surface rupture. Although the total amount of displacement on the surface also plays a role in this progress, the damage of total displacement is much smaller than that of the adjacent surface displacement difference. Thus, the adjacent surface 
displacement difference avoidance rule ensures constructions

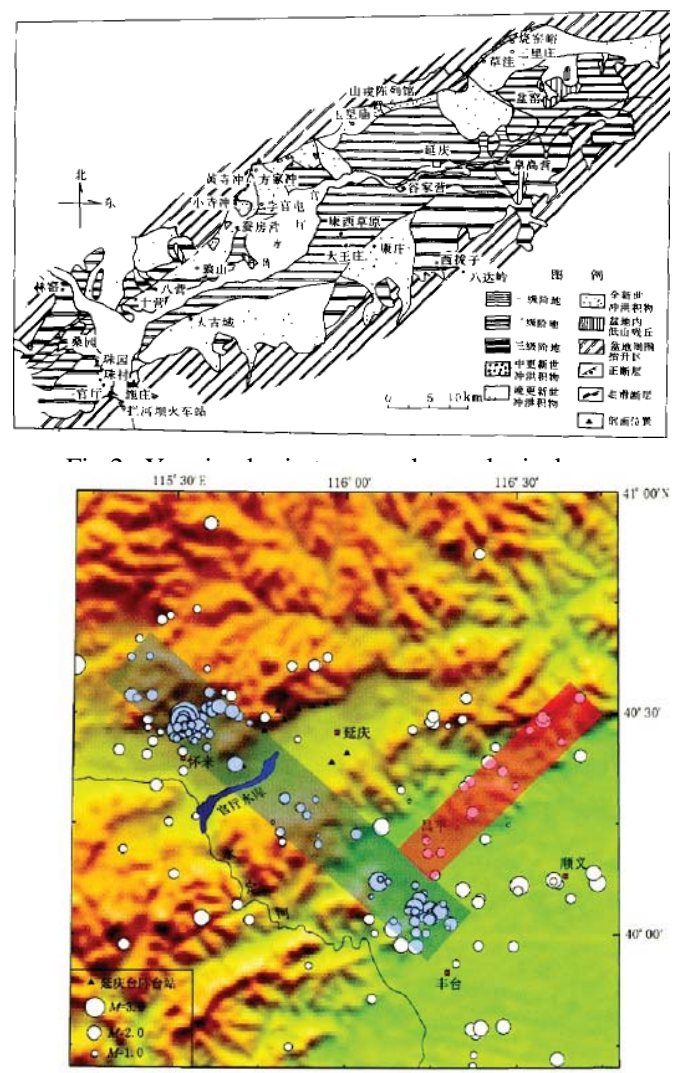

Fig.3. The map of epicentre distribution part of Beijing Xishan area safety, and greatly improves the land utilization rate.

\section{YANQING NEW CASE ANALYSIS}

\section{A. The basic situation of Yanqing district geology}

Yanqing locates in Beijing, 60km northwest in small new faulted intermountain basin, Yanqing Basin (Fig.2.). Two major active fault zones develop in this region, the NE, NNE
South Bank faults and west Shizhuang fault of Guanting reservoir.

Beiyuan Fault, a normal fault whose trend is SE in $1-2 \mathrm{~km}$ depth and dip angle is about 70 degrees. At $4 \mathrm{~km}$ from the surface rupture band, it becomes wider. With depth increasing, the crust begins brittle; rupture tendency side expansion and an inclination angle becomes slow; natural fault slip surface also transfers to ductile shear deformation, showing rotational plane rupture mode.

Shizhuang Fault goes $300^{\circ} \sim 320^{\circ}$, 16km visible length. The most typical one is East Shizhuang first Amoy, 20m deep, $2 \sim 5 \mathrm{~m}$ width, Left Lateral Anti-clockwise fault. The early fault has the characteristic of overvoltage shear, the latest strong activity happened during the middle and late Pleistocene.

\section{B. Seismic data and avoidance planning}

Fig.3. is the earthquake epicenter map of Beijing Xishan area, during October 2001 to December 2005. It concentrated in two brands, North East and North North West. Vertically, it concentrated in a region more than $10 \mathrm{~km}$, especially in $4-8 \mathrm{~km}$ with high angle (70 degrees), and it looks like a broom. This shows that the strike slip fault contains some positive component.

Calculate surface displacements of Yanqing Basin, which is named Yanqing district with area of $600 \mathrm{~km} * 1200 \mathrm{~km}$ (Fig.2.). Considering specific geological data and seismic station data, select seven representative active faults according to the locations and extensions of active faults (Fig.3., red line marker; Fault parameters, TABLE II.). Stimulate a 7.0-magnitude quake, then calculate the rupture zone (Fig.5.), to indicate the reasonable avoidance area in city. Fig.5. shows that when people choose $0.1 \mathrm{~m}$ as displacement difference to avoid it is more flexible to clarify intensity of building seismic fortification categories and regulate fault avoidance requirements. Thus, in promising to ensure the safety of the building when the earthquake happens, it can maximize the utilization rate and integrity of lands, in large extent, relieving the pressure of land intensity.

TABLE II. MAIN Active FaUlt Model Parameters IN YANQING DistRICT

\begin{tabular}{l|lllllllll}
\hline Name & $\begin{array}{l}\text { Hidden } \\
\text { Depth }\end{array}$ & Trend & Angle & $\begin{array}{l}\text { Plane } \\
\text { Extension }\end{array}$ & $\begin{array}{l}\text { Depth } \\
\text { Extension }\end{array}$ & $\begin{array}{l}\text { Moving } \\
\text { Direction }\end{array}$ & Dislocation & Rank & Hidden Depth \\
\hline B-Y 1 & $1000 \mathrm{~m}$ & $67.5^{\circ}$ & $70^{\circ}$ & $383 \mathrm{~m}$ & $1500 \mathrm{~m}$ & $-90^{\circ}$ & $2 \mathrm{~m}$ & 7 & $329 \mathrm{~km}, 145 \mathrm{~km}$ \\
B-Y 2 & $1100 \mathrm{~m}$ & $40.5^{\circ}$ & $70^{\circ}$ & $169.5 \mathrm{~m}$ & $1350 \mathrm{~m}$ & $-120^{\circ}$ & $2 \mathrm{~m}$ & 7 & $582 \mathrm{~km}, 223.5 \mathrm{~km}$ \\
B-Y 3 & $1200 \mathrm{~m}$ & $46.7^{\circ}$ & $70^{\circ}$ & $338.1 \mathrm{~m}$ & $1300 \mathrm{~m}$ & $-90^{\circ}$ & $2 \mathrm{~m}$ & 7 & $721 \mathrm{~km}, 179 \mathrm{~km}$ \\
B-Y 4 & $1300 \mathrm{~m}$ & $53.8^{\circ}$ & $70^{\circ}$ & $362 \mathrm{~m}$ & $1250 \mathrm{~m}$ & $-90^{\circ}$ & $2 \mathrm{~m}$ & 7 & $739 \mathrm{~km}, 271 \mathrm{~km}$ \\
B-Y 5 & $1400 \mathrm{~m}$ & $45.9^{\circ}$ & $70^{\circ}$ & $372 \mathrm{~m}$ & $1000 \mathrm{~m}$ & $-90^{\circ}$ & $2 \mathrm{~m}$ & 7 & $913.5 \mathrm{~km}, 476.5 \mathrm{~km}$ \\
S-Z 1 & $200 \mathrm{~m}$ & $122.7^{\circ}$ & $70^{\circ}$ & $319.8 \mathrm{~m}$ & $300 \mathrm{~m}$ & $-30^{\circ}$ & $2 \mathrm{~m}$ & 7 & $286.5 \mathrm{~km}, 273.5 \mathrm{~km}$ \\
S-Z 2 & $200 \mathrm{~m}$ & $125^{\circ}$ & $90^{\circ}$ & $183.1 \mathrm{~m}$ & $300 \mathrm{~m}$ & $0^{\circ}$ & $2 \mathrm{~m}$ & 7 & $657 \mathrm{~km}, 484.5 \mathrm{~km}$ \\
\hline
\end{tabular}

\section{CONCLUSIONS}

Through the application of previous calculation and specification, for general hidden faults, Okada Dislocation Theory can practically calculate the surface rupture zone consistent with geological situations. For avoidance areas, based on the principle of total displacement, it wastes too many lands; based on displacement difference principle, it can ensure both construction safety and land conservation. Using this new method to specific geological conditions of Yanqing, it can 
promise the safety, and land utilization rate can improve significantly. The new methods can greatly guide the urban

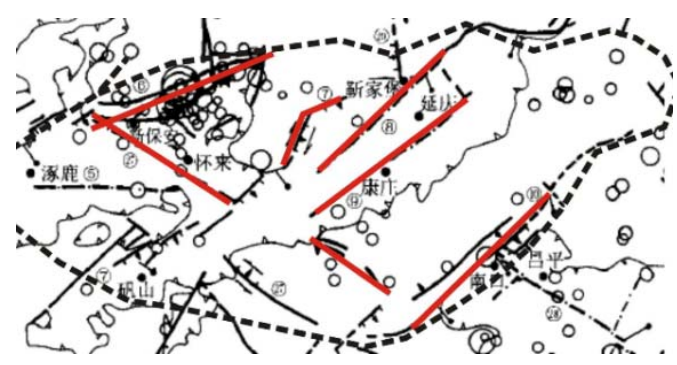

Fig. 4. Hidden Active Fault Map, Yanqing District constructions in practical application.

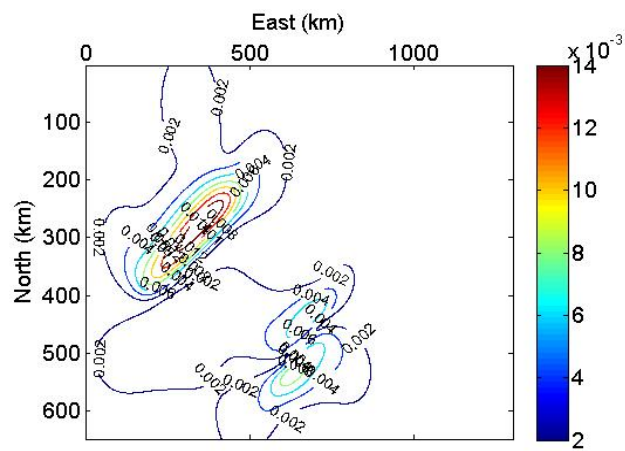

Fig. 5. Surface Displacement Difference Contour Map, Yanqing District

\section{REFERENCES}

[1] Gongming Yin, Yanchou Lu,1996, A preliminar y study on Beijing main tectonic events in Yanqing basin in 500 thousand years: NORTH CHINA EARTHQUAKE SCIENCES, no.14 (4):19-28.

[2] Peide Wang, Chunlai Li, E Wetzig, 2007, Seismic tomography method research active faults in the northwest of Beijing Province: ACTA SEISMOLOGICA SINICA, no. 29(1): 11-18

[3] The people's Republic of China Ministry of construction, 2001, GR50011-2001 GBJll: China Architecture \& Building Press.

[4] Wenke Sun, 2012, The theory of earthquake dislocation: Science Press.

[5] Xiwei Xu, Guihua Yu, Wentao Ma, 2012, Evidence and methods to determine earthquake surface rupture of active fault "Avoidance Area": SEISMIC GEOLOGY, no. 24(4), 470-481.

[6] Zhujun Han, Yongkang Ran, Xiwei Xu, 2002, A preliminary study on surface rupture zone and the dislocation width of hidden faults: SEISMIC GEOLOGY, no.24(4), 484-489.F 